NOTICE: this is the author's version of a work that has been accepted for publication in Interacting with Computers. Changes resulting from the publishing process, such as peer review, editing, corrections, structural formatting, and other quality control mechanisms may not be reflected in this document. Changes may have been made to this work since it was submitted for publication. A definitive version will be published in Interacting with Computers.

\title{
Everyday use of computer-mediated communication tools and its evolution over time: an ethnographical study with older people
}

\author{
Sergio Sayago $^{1 \mathbf{a}}$, David Sloan ${ }^{\mathbf{a}}$, Josep Blat ${ }^{\mathbf{b}}$

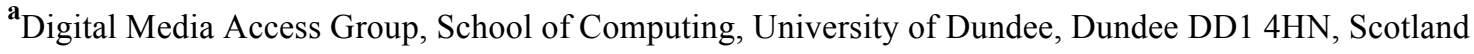 \\ (sergiosayago,dsloan)@computing.dundee.ac.uk \\ ${ }^{\mathbf{b}}$ Interactive Technologies Group, Universitat Pompeu Fabra, RocBoronat138 E-08018, Barcelona, Spain \\ josep.blat@upf.edu
}

\begin{abstract}
Based on a 3-year ethnographical study, this paper discusses the prolonged use of Computer-Mediated Communication (CMC) tools by approximately 400 older people in an adult education centre in Barcelona (Spain). Contrary to oversimplified views of older people as ICT users, this paper shows that they make a very rich use of CMC tools. Relevant elements of this use are their permanent desire to feel and be included, social, independent and competent ICT users. Despite the numerous interaction issues they face when using ICT, some are constant across different tools. Difficulties due to cognition limit their interactions more severely than those problems due to perceiving visual information or using the mouse. By examining the longitudinal aspect of the study, this paper addresses the evolution of technology use and whether the interaction issues that most of the current older people exhibit will be relevant when today's more ICT literate young adults grow older. Interaction issues due to cognition are time-persistent, and independent of both experience and practice with ICT. Difficulties reading from the screen or using input devices are overcome with ICT experience. The strategies adopted by older people for coping with all these interaction issues are always targeted at feeling and being included, social, independent and competent ICT users. The results deepen current understanding of tools use in connecting older people with their social circles and the interaction issues most of them encounter when using ICT. The results also suggest that cognitive-related problems will be the most important ones in our work with the next generation of older people.
\end{abstract}

Keywords: ethnography, evolution, computer-mediated communication, technology use, interaction, older people

\section{Introduction}

An increasing ageing population and the importance of Information and Communication Technologies (ICT) in daily living have strengthened the need for further Human-Computer Interaction (HCI) research with older people. This paper discusses the prolonged use of Computer-Mediated Communication (CMC) tools in out-of-laboratory conditions by 388 older people, aged 58-77, by analysing the data of a 3-year ethnographical study.

A previous paper, which was based on the same ethnographical study, focused on their everyday e-mail use [33]. The results showed that three key elements of this use are socialisation, inclusion (i.e. using the same technologies as the most important members of their social circles - grandchildren, children and close friends), and independence (i.e. not relying on anyone else). Age-related changes in functional abilities and overall lack of ICT skills [21] are barriers to technology use, and the paper showed that those related to cognition limit more severely the use of e-mail tools by older people than others due to problems perceiving visual information or using the mouse.

This paper extends [33] in two key directions. We discuss the everyday use of other CMC tools. For instance, older people make the effort to learn and use video chats (rather than e-mail) to keep in touch with their young grandchildren (aged 5-9) because video chats allow more natural and effective communication with them: "I chat with my grandchildren rather than e-mailing [...] They're between 7 and 9 and you should think that both are learning to write at school, so e-mailing is more difficult for them than talking to me!" We argue that the use of these and other tools is very rich, contrary to oversimplified views of older people as ICT users. These results confirm that socialisation, inclusion, and independence are not exclusive to e-mail use.

\footnotetext{
${ }^{1}$ Corresponding author. E-mail: sergiosayago@computing.dundee.ac.uk. Phone: +44 (0)1382 385598. Fax: +44 (0)1382 385509 [FAO: Dr Sergio Sayago]. Postal address: Dr Sergio Sayago, School of Computing, University of Dundee, Dundee DD1 4HN, Scotland, UK

Please cite this version of the manuscript as: Sayago, S., Sloan, D., Blat, J. Everyday use of computer-mediated communication tools and its evolution over time: an ethnographical study with older people. Interacting with Computers, http://dx.doi.org/10.1016/j.intcom.2011.06.001
} 
NOTICE: this is the author's version of a work that has been accepted for publication in Interacting with Computers. Changes resulting from the publishing process, such as peer review, editing, corrections, structural formatting, and other quality control mechanisms may not be reflected in this document. Changes may have been made to this work since it was submitted for publication. A definitive version will be published in Interacting with Computers.

We also address the evolution of both the interaction issues faced by older people and the strategies they adopt to overcome them with increasing ICT experience. Whilst the evolution of interactions has recently attracted research (e.g. [22]), this is not widely covered in HCI research with older people. However, addressing this issue should help us answer the important question of which of the problems older people encounter are due to a lack of ICT skills, and which are due to ageing. The former are exhibited by most of the current cohort of older people. The latter are expected to remain valid when most of today's young adults, who are comfortable with contemporary ICT, grow older and deal with new interactive technologies [18].

We argue that difficulties due to cognition (e.g. difficulties remembering steps) are timepersistent, independent of experience and practice with ICT. However, difficulties due to perceiving visual information or using the mouse are overcome with ICT experience. "I was all thumbs but with time, I've learned how to master the mouse and created my own way of playing with this little beast [...] but I still need to take notes, because I keep forgetting how to do things".

The rest of the paper is organised as follows. Section 2 reviews previous work on CMC tools and interaction evolution with older people. Section 3 describes the ethnographical study and the method of collecting and analysing the data. Section 4 presents the results on use. Section 5 addresses key interaction issues across tools. Section 6 discusses the evolution of interaction issues and strategies to deal with them over time. Section 7 gives some examples of implications for understanding, designing and evaluating older people's experiences with CMC tools. Section 8 discusses the research focus, methods, results and limitations. Section 9 presents the main conclusions, ongoing and future work.

\section{Related work}

\subsection{Everyday use of CMC tools by older people}

HCI research with older people on CMC has generally focused on the design of new tools or more accessible versions of current ones, and on examining how they use CMC tools. Older people's perceptions and attitudes towards using them have also been explored. Our review of this research, which is discussed next, shows that very little is known about CMC tools use by older people in out-of-laboratory conditions. However, as argued in [33] and [4], understanding how (older) people use ICT in real-life settings is crucial to design better technologies.

\subsubsection{New or more accessible versions of tools}

A number of studies have focused on improving the accessibility of both existing and important tools for older people, such as e-mail systems (see [33] for a review) and instant messaging [30]. The approach adopted in these studies is to compensate for age-related changes in functional abilities and lack of ICT experience, resulting in simpler tools. Whereas such an approach concurs with the one adopted in mainstream HCI research with older people, it does not sufficiently consider their everyday interactions with ICT [33].

New tools have been designed to facilitate different forms of (extended) family communication, for instance by sharing photos and calendar information (e.g. [6], [25], [28]). The approach adopted in these studies is to exploit patterns of daily conversations. Innovative interaction paradigms have emerged from this approach, which could aid the incorporation of these tools into everyday life.

\subsubsection{Studies of use of current tools}

A number of studies have explored how older people use existing CMC tools to communicate with their social circles. Through semi-structured ethnographical interviews with 31 older people, observations of conversations in voice chat rooms and messages in an online forum, Xie [42] found that the voice chat room was used for companionship (emotional support) whereas the text messages were used for information. Through a household survey, [35] showed that the

Please cite this version of the manuscript as: Sayago, S., Sloan, D., Blat, J. Everyday use of computer-mediated communication tools and its evolution over time: an ethnographical study with older people. Interacting with Computers, http://dx.doi.org/10.1016/j.intcom.2011.06.001 
NOTICE: this is the author's version of a work that has been accepted for publication in Interacting with Computers. Changes resulting from the publishing process, such as peer review, editing, corrections, structural formatting, and other quality control mechanisms may not be reflected in this document. Changes may have been made to this work since it was submitted for publication. A definitive version will be published in Interacting with Computers.

most popular Internet application, sending and receiving e-mails, occurred at home, where support was usually available from the immediate household and relatives. Through questionnaires, [31] revealed that older people e-mailed their grandchildren who lived far away more frequently because this avoided the experience of telephoning, while grandmothers were more frequent users than grandfathers. In a field trial with 77 people, [1] explored the benefits of video chats with their families. The 2 grandparents who participated in this study reported playing a large role in the lives of their remote grandchildren thanks to video chats. Through interviews with 28 American parents and grandparents in a laboratory setting, [37] found that phone and e-mail communication were the most popular technologies, whereas instant messaging was only used in $15 \%$ of the relationship pairs.

These studies offer valuable but partial information. Surveys show general trends without enough focus on the fine details and complexity of daily use. Studies involving family communication do not describe the use of CMC tools by the grandparents.

\subsubsection{Studies of perception and attitudes towards using current tools}

Other studies have examined the perceptions and attitudes of older people towards using CMC tools to communicate with their social networks. Gibson et al [17] explored the perceptions of 17 older people who were active Internet users towards MyFriendsOnline and FaceBook. Discussions in two focus groups revealed that, for instance, they were anxious to retain their privacy and afraid of identity theft. Pfeil et al [29] conducted 31 semi-structured interviews to investigate needs and preferences concerning online social support, finding that the exchange of light support online was important in the everyday lives of older people, who felt uneasy building trust with people they do not know. Lindley et al [25] conducted three focus groups which explored the attitudes of 18 older people towards keeping in touch with people who were important to them. They found that older people aim to communicate with a level of dedication that cannot be supported through lightweight technologies, which are predominantly used by younger generations. Older people also wanted to be able to respond to any form of contact without being intrusive. Dickinson and Hill [13] interviewed 9 older people to compare their use of e-mail, traditional mail and telephone, finding that the use of technology was inversely related to the amount of effort needed.

Only in few of the studies reviewed in Sections 2.1.2 and 2.1.3 [1, 17, 25, 42], the opinions of older people were somewhat supported by in-situ observations, and this limits the validity of the results.

\subsection{Evolution of technology use over time}

The evolution of older people's interactions with ICT is at the centre of current socio-technical research aimed at accommodating their dynamically changing accessibility needs [36]. The temporal aspect of interactions is also receiving growing attention in user experience research [22]. However, "studies of HCI involving time are rare" [20, p. 21]. Turner et al [39] is an exception and focused on how older people who start to use computers account for the difficulties they encounter in doing so. The analysis was based on conversations in discussion groups conducted during 9 months with 20 older people.

Whilst the problems faced by older people learning to (and using) ICT are not limited to physical and cognitive factors - other issues are, for instance, the cost of the technology, its availability and access to it [12,39], most of the interaction issues that those who are using ICT experience are related to age-related changes in functional abilities and overall lack of ICT skills [33].

By reviewing literature on ageing and web accessibility for older people, Hanson [18] argued that, despite being more skilled in ICT, the next generation of older people will probably find themselves confronting new and unfamiliar ICT. We build on this argument by discussing more precise questions, which have not been addressed to date. For instance, are difficulties using

Please cite this version of the manuscript as: Sayago, S., Sloan, D., Blat, J. Everyday use of computer-mediated communication tools and its evolution over time: an ethnographical study with older people. Interacting with Computers, http://dx.doi.org/10.1016/j.intcom.2011.06.001 
NOTICE: this is the author's version of a work that has been accepted for publication in Interacting with Computers. Changes resulting from the publishing process, such as peer review, editing, corrections, structural formatting, and other quality control mechanisms may not be reflected in this document. Changes may have been made to this work since it was submitted for publication. A definitive version will be published in Interacting with Computers.

input devices, perceiving visual information and remembering how to conduct tasks timepersistent (i.e. independent of ICT experience), or do they wear off with increasing ICT experience? How do the strategies adopted by older people to overcome these problems change when their experience with ICT increases? The answers can deepen current understanding of interaction evolution with today's older people by distinguishing between problems due to a lack of ICT skills and ageing. The answers can also help predict difficulties that the next generation of older people will probably encounter.

We provide some answers to these and other questions by drawing upon a 3-year ethnographical study of ICT use by older people in out-of-laboratory conditions. This study is described next.

\section{Extended ethnographical study}

Over three years (2005-2008), we conducted a classical ethnographical study. Unlike forms of ethnographical research developed for integrating better ethnography into HCI developments, such as quick-and-dirty, concurrent and evaluative ethnography [32], classical ethnography requires from 6 months to 2 years or more in the field [16]. Given the lack of ethnography in HCI research with older people, and our perception that their use of ICT had not been understood well enough, we decided to conduct classical ethnography.

The study combined first-hand observations of and conversations with 388 older people while using several ICT, ranging from e-mail tools and video chats to web browsers and wordprocessing tools, in courses, workshops, public meetings and drop-in sessions in Àgora ${ }^{2}$ (Barcelona, Spain). For ten months of each year, we met the participants up to two or three times a week for up to two to three hours each time, resulting in some 720 hours of fieldwork. 20 participants attended Àgora regularly (2-3 times per week), they were enrolled in several courses at the same time and participated in all public meetings and workshops organised throughout the study. The rest enrolled in one or two courses a year and went to Àgora weekly to use ICT in drop-in sessions. They also attended meetings and/or workshops when these activities did not prevent them from conducting others (e.g. visit to the GP, travelling or taking care of grandchildren). Table 1 (Appendix I) gives more details of the ethnographical implementation.

Most of the participants (90\% aged 58-70; 10\% aged 70-77) had low literacy levels (only $10 \%$ went to secondary school) and little experience with ICT (38 were familiar with basic ICT concepts through the use of computers in their previous jobs). All participants lived in Barcelona: 30 with their children and the rest either alone or with their partners. Most participants (c. 300) had family who lived locally, in Barcelona and towns nearby. Other participants had family further a field, in Catalonia and other Spanish regions.

We recorded written fieldnotes of all our observations and conversations, since we found that all the participants wrote down their notes by using paper and pencil. They were also used to seeing other people, such as those in charge of the computing courses, taking paper-based notes. The use of laptops might therefore have been intrusive in this context. Also, there were no laptops in the computer or lecture rooms.

We analysed the data by conducting open, axial and selective coding, and the constant comparative technique of the Grounded Theory approach for qualitative analysis in ethnography [8]. This consisted of reading the entire fieldnotes to gain an overall sense of the data, which was followed by an initial code list of the fieldnotes (open code). This list was adapted from the

\footnotetext{
${ }^{2}$ http://www.edaverneda.org. Àgora believes in empowering their members, especially older people. They term them 'participants' to stress this fact and their involvement in the activities organised in Àgora, e.g. the participants decide what ICT they want to learn and use in computing lessons. We use the term 'participants' throughout the paper with this double meaning. Meetings are organised monthly to discuss the positive and negative aspects of the courses and activities carried out. They provide also an opportunity to discuss aspects of the use of ICT in which participants have a special interest. Workshops are hands-on sessions on technologies that are very popular among participants.

Please cite this version of the manuscript as: Sayago, S., Sloan, D., Blat, J. Everyday use of computer-mediated communication tools and its evolution over time: an ethnographical study with older people. Interacting with Computers, http://dx.doi.org/10.1016/j.intcom.2011.06.001
} 
NOTICE: this is the author's version of a work that has been accepted for publication in Interacting with Computers. Changes resulting from the publishing process, such as peer review, editing, corrections, structural formatting, and other quality control mechanisms may not be reflected in this document. Changes may have been made to this work since it was submitted for publication. A definitive version will be published in Interacting with Computers.

participants' language. We then discussed this list amongst ourselves until the analysis, in our opinion, had reached theoretical saturation. Next, we established categories and the relationship between them.

In [33], the analysis was conducted while gathering the data and some peculiarities in the use of different CMC tools were detected. This paper is based on a re-analysis of the whole corpus of fieldnotes, which is another common approach in classical ethnographical research [16], explores the everyday use of more CMC tools and the temporal evolution of this use.

The core categories that emerged in the study of e-mail use [33] are also relevant to reveal and explain the use of other CMC tools. New categories have been identified and others have been refined as a result of considering the use of more tools and its evolution. These categories are indicated in italics in the following list:

- Rich use of CMC tools: effort; competent use; social circles; frequency of use; type of use and objective of the communication; geographical distance; socialisation; isolation; feeling of being alive; experience and relationship with other technologies; emotion; accomplishment

- Interaction issues: persistent and temporal problems; excessive functionalities; independence; inclusion; consistency; life experience; terminology; vision; remembering steps; input devices, note-taking; clickable areas; free time use, priorities in daily life

The categories excessive functionalities, free time use, and priorities of daily life, are part of interaction issues in this paper. We consider that they are crucial aspects in understanding the evolution of technology use. TV and phone are changed for other technologies because of widening the focus on tools. The prolonged use of different tools, and the resulting richer results (we believe) motivated us to change the name of the core categories: Rich instead of Nature of, and issues rather than barriers.

\section{Rich use of some CMC tools}

This section discusses the use of video chats, weblogs (blogs) and computer tools for creating multimedia presentations. These tools emerged from the analysis described in Section 3.

\subsection{Older people adapt to their interlocutors as they want to be socially included, and this is worth the effort}

We observed that 350 participants did use video chats (e.g. Skype) rather than e-mail to keep in touch with their grandchildren (aged 5-9) on a regular basis (once a week or a fortnight) in 2030 minute sessions. They reported that writing (e-mailing) was a much bigger effort for their young grandchildren (low literacy) than chatting.

[Man B, 72]: I chat with my grandchildren rather than emailing them, however.

[Researcher]: How come?

[Man B, 72]: My grandchildren are between 7 and 9. You should think that both (name of his grandchildren) are learning to write at school, so e-mailing is much more difficult for them than speaking... indeed, they talk quite a lot!

However, the same participants both preferred and used e-mail for asynchronous communication with their grandchildren aged $10+$. This finding both concurs with and partly contradicts [1], wherein it was found that grandchildren were the main motivation for their grandparents to use video chats. Our results indicate that this depends strongly on the grandchildren's age and literacy.

Whereas e-mail opens up both a new and rich communication channel with close friends and children [33], all the participants reported that they did not use video chats (even the telephone) to communicate with their children because of their hectic work, study and social agendas.

Please cite this version of the manuscript as: Sayago, S., Sloan, D., Blat, J. Everyday use of computer-mediated communication tools and its evolution over time: an ethnographical study with older people. Interacting with Computers, http://dx.doi.org/10.1016/j.intcom.2011.06.001 
NOTICE: this is the author's version of a work that has been accepted for publication in Interacting with Computers. Changes resulting from the publishing process, such as peer review, editing, corrections, structural formatting, and other quality control mechanisms may not be reflected in this document. Changes may have been made to this work since it was submitted for publication. A definitive version will be published in Interacting with Computers.

These aspects hinder synchronous communication. Participants considered video chatting an awkward way of communicating with close friends.

[Man A, 67]: I don't chat with my grandchildren. I write e-mails to them. My grandchildren are teenagers and adults. Chatting is something embarrassing for the younger ones, I think. They're always telling me that they're going on a date or they're going out with their friends. They prefer the e-mail, so I e-mail them as I don't want to lose contact. Older ones, even my children, have no time to chat with me, however. The email is something more suitable since they're working long hours and have almost no free time. They use the e-mail at work, so they find it easier to email me rather than setting up a time to chat.

We also observed that 50 participants met up in cybercafés or libraries nearby when they could not use video chats in Àgora (for instance, due to slow Internet connection or no computer available).

[Woman R, 75]: Last Sunday I had a chat with my granddaughter.

[Researcher]: Do you mean that you met up with her in Àgora?

[Woman R, 75]: Skype, I mean. I went to the cybercafé near my home with (name of participant). Skype did not work well last week in Agora, so we decided to go to another place. It's perfect to have Skype working well in this cybercafé when you know you might have problems in Agora - we use the computers so much that we break them (smile). We met up on Sunday morning, had a chat with my granddaughter, with the computer I mean, and later we went for a coffee with (name of participant). It was a lovely Sunday morning!

These results contradict [13]. Our participants do make the effort of (learning to) using those $\mathrm{CMC}$ tools that allow their grandchildren, children and close friends to communicate with them in the most natural and/or effective way. They even go where the technology is ready to use. These different results might be due to their motivation for not losing contact with their loved ones.

\subsection{Older people use CMC tools as they help them feel closer and important to their loved ones}

Video chats with young grandchildren included parents, who helped them set up the sessions and wanted to control their online activities. Regardless of frequency and duration, all the participants considered these exchanges with the closest family very valuable moments. They reported feeling still important and cared.

[Woman W, 67]: Do you know the best thing of chatting with my young grandchildren?

[Researcher]: I haven't the foggiest idea ...

[Woman W, 67]: I can both see and talk to my children, as they're keeping control over what their son is doing online and they give him a hand as well. I feel much closer to them, and you will know how important this is when you become older and a granddaddy!

The role of parents in preparing video chat sessions and the feeling of importance within the family concur with the findings of [1], although in our study the participants did not play games through video chats, unlike in [1]. Participants reported that their grandchildren showed them what they had done in school or the important discoveries they had made that day or week. This difference might be cultural or due to the distance factor. Most of our participants had face-toface contact with their grandchildren weekly or monthly, while older people in [1] lived very far away from them.

Face-to-face or phone conversations were not substituted for video chats. Participants reported that their video chats became the topic of their face-to-face or phone conversations with their grandchildren and children. E-mail tools did not replaced, (but instead, reinforced) other

Please cite this version of the manuscript as: Sayago, S., Sloan, D., Blat, J. Everyday use of computer-mediated communication tools and its evolution over time: an ethnographical study with older people. Interacting with Computers, http://dx.doi.org/10.1016/j.intcom.2011.06.001 
NOTICE: this is the author's version of a work that has been accepted for publication in Interacting with Computers. Changes resulting from the publishing process, such as peer review, editing, corrections, structural formatting, and other quality control mechanisms may not be reflected in this document. Changes may have been made to this work since it was submitted for publication. A definitive version will be published in Interacting with Computers.

communication channels [33]. These results were independent of the distance from the grandchildren.

[Researcher]: Wow, this must be very important, although I guess you use less the phone or your face-to-face contact with them

[Woman W, 67]: Not at all! Video chats will never replace their visits, or me paying a visit to them. When we meet, we do talk about our video chats... as I told you, I feel much closer to them!

Xie [42] found that video chats had a stronger emotional component than textual messages in online conversations with friends. However, when comparing communications mediated by email and video chats, both tools help older people feel closer, useful and still important for their loved ones.

\subsection{Older people socialise while using tools and put something of themselves into communication}

"A recent trend in CMC is the widespread adoption of 'blogging' (or writing of web logs)" [38, p. 229]. In this section we discuss older people's use of weblogs (blogs), computer-aided tools for creating text, multimedia presentations and video chats, showing that socialisation is a key and common element in their usage.

We observed how a group of 18 participants set up a blog, using Blogia ${ }^{3}$, and used it during two courses. Each course lasted 6 months. The participants discussed together all the steps required to create the blog and posted messages in pairs: one was writing whereas the other was thinking aloud about what to write. This pair-based interaction occurred before, during and after the courses. We observed them meeting up to post messages they did not finish in the sessions, or read the ones posted by other participants. The content of the posts was related to the dynamics of the courses and tips to help others conduct difficult tasks, such as attaching photos to e-mails. These results stress the importance of "putting something of themselves into communication" [25] in blogs too.

Whilst computer tools for creating multimedia presentations are not amongst the technologies which tend to attract $\mathrm{CMC}$ research ${ }^{4}$, our participants used them to support communication, both face-to-face and online. 350 of our 388 participants created presentations in Àgora with their close friends 2-3 times a week (weekends included) by using MS PowerPoint and Windows Movie Maker. They used family photos, photos they took during their holidays and pictures downloaded from the web ${ }^{5}$. We observed that participants explained how they had created these presentations to others in courses, workshops and drop-in sessions, and showed them in social events organised in Àgora - in addition to exchanging them with close friends by e-mail. Participants reported using the presentations in get-togethers (e.g. birthdays) as well. The use of tools and social practices around it reinforced friendship and family ties. Participants also reported watching much less TV, since they felt more useful when creating and sharing multimedia presentations with friends, concurring with [33].

[Man G, 67]: I've finished my presentation with the photos of the sport competition my granddaughter won last weekend. Do you want to come over and have a look? [Man F, 70]: Did you do this wonderful presentation alone? I want you to send it to me by e-mail right now! You know that my wife loves these things. [Man G, 67]: I spent...don't know...may be 2 or 3 hours with him in Agora yesterday. You didn't come, remember? You missed it! I'll explain to you

\footnotetext{
3 http://www.blogia.com/

${ }^{4}$ Technologies much more explored are, for instance, e-mails, blogs, chat and instant messaging, metaworlds and personal homepages [38]

${ }^{5}$ Photos have been shown to enhance and support family communication $[6,28]$ concurring with our results, where users' participation is a lot more active

Please cite this version of the manuscript as: Sayago, S., Sloan, D., Blat, J. Everyday use of computer-mediated communication tools and its evolution over time: an ethnographical study with older people. Interacting with Computers, http://dx.doi.org/10.1016/j.intcom.2011.06.001
} 
NOTICE: this is the author's version of a work that has been accepted for publication in Interacting with Computers. Changes resulting from the publishing process, such as peer review, editing, corrections, structural formatting, and other quality control mechanisms may not be reflected in this document. Changes may have been made to this work since it was submitted for publication. A definitive version will be published in Interacting with Computers.

how to do this thing, moving the pictures, I mean. And I'll send it to you by email so that you can show it to your wife, don't worry!

Video chats were carried out in social places (e.g. Àgora), with close friends or in company of them, since participants had social support and were not alone at home. We observed that close friends were actively involved in some parts of the video chats conducted by participants with grandchildren living in Barcelona. They reported that their friends took part in everyday conversations with their grandchildren when they knew them enough, so social practices were mapped onto online ones in a natural way - video chats allowed this mapping. We also observed that close friends were listeners in the video chats conducted by participants with grandchildren living out of Barcelona.

[Researcher]: Sorry to disturb both of you, but it has come to my attention that you two are talking to the computer!

[Man T, 70]: Yes, indeed! (smile) We're having a conversation with his grandson, who is spending his weekend with his parents in the north of Catalonia.

[Researcher]: But I'd swear that both of you're talking to him.

[Man R, 72]: That's true, boy. We're very good friends and he knows my grandson. We live in the same neighbourhood and we go to the same park with our grandchildren, so... we talk together and also help each other. You never know when the computer will tell you something you won't understand at all, and two brains work better than one!

Even apparent exceptions confirm the relevance of socialisation. We observed and talked with 300 participants while playing either computer (e.g. chess, solitaire) or online games (most commonly, Mahjong Titans) occasionally, before or after the courses, in 10-minute sessions at most. They played these games individually. However, they reported playing them only to relax after a hard session, when they were bored or waiting for a friend to come along.

[Woman R, 74]: I'm playing the game in which you've to match pairs of the same key...see, this one

[Researcher]: Do you know you can play online?

[Woman R, 74]: I think so, but...oh, no! I play when I'm bored and don't know what to do with the computer or... like today, when I'm waiting for her to come to a session, she is always late! I don't want to be hooked at games and be alone at home playing games. I've a lot of time and do want to see and talk to people. This makes me feel alive!

The participants considered playing games an activity which fosters isolation ${ }^{6}$ and was easily replaced with a more social one.

[Researcher]: I didn't know you play online games?

[Man J, 69]: I don't. I'm waiting for my classmate and I was wasting my time with the solitaire

[Researcher]: It's ok. You can play until the start of the session.

[Man J, 69]: Yes, sure, this is the most useful thing. I'll close the screen now, okay. I prefer to talk to you rather than playing solitaire. I do that when I'm bored or waiting for someone else. Last week I put a photo of mine that moved around the screen in a presentation and showed it to my family in a birthday party.....we spent the whole afternoon talking about computers and the new mobile phones...the ones with an apple at the back... and I took part in the conversation!

Our observations of playing computer games as an interim activity between social interactions does not concur with the one reported in [41], wherein five older people living in a retirement

\footnotetext{
${ }^{6}$ They were aware of other games, such as those advertised on TV targeted at older people, and of the possibility of playing games with other people (e.g. online chess). However, they played none of them.

Please cite this version of the manuscript as: Sayago, S., Sloan, D., Blat, J. Everyday use of computer-mediated communication tools and its evolution over time: an ethnographical study with older people. Interacting with Computers, http://dx.doi.org/10.1016/j.intcom.2011.06.001
} 
NOTICE: this is the author's version of a work that has been accepted for publication in Interacting with Computers. Changes resulting from the publishing process, such as peer review, editing, corrections, structural formatting, and other quality control mechanisms may not be reflected in this document. Changes may have been made to this work since it was submitted for publication. A definitive version will be published in Interacting with Computers.

community had learned to play console games as part of that community's weekly or bi-weekly activity schedule. This difference might be due to contextual and cultural differences. However, our results reinforce that supporting social contact (and communication) is a crucial element in designing computer games, especially for older people. This also concurs with [41] and other studies, such as $[23,25,40]$.

To sum up: socialisation, which happens at different levels, ranging from pair-based interactions while blogging to using video chats in social places and in company of friends, is a hallmark of the everyday use of different CMC tools by our participants.

\subsection{Older people are interested in tools; show them and they will decide how (not) to use them}

200 participants were interested in learning more about blogs. They reported having heard about them in Àgora and mass media (newspapers and TV news). We set up hands-on sessions up aimed at showing them a variety of examples (e.g. using the blogs section in Google) and discussing the main differences and similarities between blogs and other more familiar technologies (letter, diary) - as indicated in guidelines for training older people in ICT [11]. Our observations and conversations revealed that no participant used blogs to communicate with their grandchildren or children: e-mail provided them with a feeling of being read that blogs did not $^{7}$.

[Researcher]: You are going to blog your children or grandchildren now, aren't you?

[Woman A, 60]: I don't think I'm going to use blogs to communicate with my people...I prefer my e-mail

[Researcher]: Why not?

[Woman A, 60]: Because when you write e-mails, you write them to somebody. I mean, you've this person in your mind. With blogs, I think that you just write your stuff, you leave it there and if somebody feels like, he or she'll read what you've written.

This finding might be expected, since e-mail tools and weblogs support different types of communication. Keeping in touch with communities, either next door or far away, is one of the key uses of blogs [38] by more ordinary users [14], such as younger people. Our participants understood that they could use blogs to help them be more connected with their close friends while working in projects. Participants usually worked on documents and presentations with pictures related to their hobbies. They shared their projects as e-mails attachments, and deemed that blogs could help them avoid managing them, which is one of the most difficult e-mailing tasks for older people [33].

Privacy and security issues appeared in the discussions. Participants reported that they would not use blogs as a personal diary. Giving personal information to people they did not really know was regarded as both dangerous and pointless, concurring with [17] and [29]. The concern for privacy and security appears in Boyd's ethnographical study of American teens' engaged with MySpace [5], but they take a more open attitude. Our participants' unwillingness to reveal personal data was strongly associated to their lifelong experiences. Yet, they did not object to other people seeing their projects online. Sharing their experiences with and learning from others in blogs related to their interests (e.g. travelling, sports, cooking) was considered an opportunity for personal growth, which highlights again the importance of socialisation.

[Man D, 65]: Let me tell you something, (name). I don't want people to know about my life. I'm old and I've seen life in many different colours. Young people don't care about privacy online, but I only share details of my life with people I trust, and the web is full of people I don't know at all.

\footnotetext{
${ }^{7}$ The concept of subscribing to RSS of blogs was never discussed because we decided to focus more on key blog activities of authoring and reading.

Please cite this version of the manuscript as: Sayago, S., Sloan, D., Blat, J. Everyday use of computer-mediated communication tools and its evolution over time: an ethnographical study with older people. Interacting with Computers, http://dx.doi.org/10.1016/j.intcom.2011.06.001
} 
NOTICE: this is the author's version of a work that has been accepted for publication in Interacting with Computers. Changes resulting from the publishing process, such as peer review, editing, corrections, structural formatting, and other quality control mechanisms may not be reflected in this document. Changes may have been made to this work since it was submitted for publication. A definitive version will be published in Interacting with Computers.

[Man T, 69]: I agree with you on that. However, don't you think that it would be nice to share your interests with other people or even...I don't know how to say this... help them to solve their problems, learn new things from them...I go cycling every week and I'd like to know more about this sport, you know, routes, bikes, all that stuff!

[Man D, 65]: Absolutely! I love cooking and I'm also in the quest of new recipes!

\section{Relevant interaction issues across CMC tools}

Important elements of tools use by older people, such as meaning, motivation, effort, perception of usefulness and feeling of being cared and still important, have been discussed in Section 4. This section focuses on other relevant elements of tools (and ICT) use. These elements, which are also crucial in understanding the evolution of technology use (Section 6), are related to the interaction issues faced by older people due to age-related changes in functional abilities and overall lack of ICT skills. Most of the interaction issues found in the study of e-mail use [33], which are reviewed in this section, such as excessive and inappropriate functions, the importance of avoiding making mistakes and the relative relevance of cognition over vision, are confirmed by this analysis. We also see other issues emerging, especially the role of notes, which are the main artefacts [3] created and used by our participants.

\subsection{Excessive and inappropriate functions}

All the participants (388) reported that CMC tools provided them with functions that they would never use, such as Bcc in e-mail, sharing documents in video-chats, creating hyperlinks in multimedia presentations and uploading a video in blogs. They also pointed out that many functions made their learning very difficult, even impossible.

\subsection{Do not hurry: errors are more important than time}

Being efficient is much less important than avoiding making mistakes. Efficiency and rush are contrary to our participants' intended pleasant and meaningful use of tools. Solving mistakes places extra cognitive demands and requires more efforts, and making errors frustrates their desire to be and feel independent and competent users.

\subsection{Using devices: the mouse is more difficult to use than the keyboard}

Whereas no participant had difficulties using the keyboard to post messages in blogs, create multimedia presentations and write e-mails, all of them had difficulties moving the mouse, double-clicking and clicking where they wanted to click, especially in menus with multiple suboptions (e.g. File $>$ New $>$ Message / Folder / Contact).

\subsection{Perceiving visual information is less difficult than learning and remembering}

Most of the participants (300) relied on their reading glasses to use different technologies, ranging from standard-sized video-chats to their own mobile phones, which were not designed for older people. No participant used screen magnifiers to use the tools throughout the study, despite the fact that they were aware of and used them at some point (see Section 6).

However, all the participants had difficulties remembering how to conduct tasks and when to left or right click. These difficulties limited their desire to be and feel independent ICT users. Their strategy for learning and remembering was to take notes, which were very important and fostered socialisation:

1) We observed that the participants became regularly nervous, and they reported feeling unable to carry out tasks, when they had left their notes at home. This was independent of ICT experience. We observed that this 'feeling unable' increased their reliance on us (and other participants) to conduct tasks.

[Woman T, 65]: Damn, I've left my notes at home!

[Researcher]: You don't need them; you know how to post a comment in the blog

Please cite this version of the manuscript as: Sayago, S., Sloan, D., Blat, J. Everyday use of computer-mediated communication tools and its evolution over time: an ethnographical study with older people. Interacting with Computers, http://dx.doi.org/10.1016/j.intcom.2011.06.001 
NOTICE: this is the author's version of a work that has been accepted for publication in Interacting with Computers. Changes resulting from the publishing process, such as peer review, editing, corrections, structural formatting, and other quality control mechanisms may not be reflected in this document. Changes may have been made to this work since it was submitted for publication. A definitive version will be published in Interacting with Computers.

[Woman T, 65]: Yes, I need them! I don't remember everything and get stuck when overcoming errors because I think I'm following the correct order of steps; why do you think I use the notes everyday, my friend?

2) The participants shared their notes (in the computers room, bar or corridors of Àgora) with those who did not attend a previous session so that they could catch up. This social use of notes resonates with the tools use described in Section 3.

[Man F, 70]: Do you have your notes here? I couldn't come yesterday and I don't know how to cut an area of an image with MS Paint to put it in this presentation for my daughter's birthday.

[Man X, 73]: Yes, sure. Have a look at mine. It's a bit difficult to do, you'll see

[Man F, 70]: I suspect so, but it'd be much more difficult without our notes. They're our memory, which fails more often than not (smile)

\subsection{Terms, icons and areas}

Due to the pervasiveness and importance of their notes, we read a random sample of 100 notebooks and identified their main and most common elements. These were: 1) textual descriptions of the steps to conduct tasks in order (e.g. numbered lists or every step in a separate line); 2) sketches of the important areas of interfaces (e.g. where to click to do or find ' $x$ '); and 3) explanations of words (computer jargon) that were especially difficult for them to understand, such as default in dialog boxes, attach in e-mail and hyperlink in multimedia presentations.

Only the icons of computer programs, such as the W of MS Word or S of Skype, appeared as such in their notes. For other icons, such as Save or Copy, the participants drew the area where to click and a textual description of the action to do (e.g. click on the top-left hand side to save). By contrast, the meaning of both interface areas, such as the log on and off areas, and computer terms, such as those stated in Section 5.5, abounded in the notes. This finding extends the importance of terms over icons found in the study of e-mail use [33] across different tools and corroborates the results of an experimental study of filling in online forms by older people [34] $]^{8}$. It also supports the recommendation of avoiding technical jargon in user interface design guidelines for them [11], wherein the concept of interactive areas is not addressed.

\section{Evolution of interaction issues and strategies over time}

This section examines how the issues raised in Section 4 and 5 evolve as the experience of older people with ICT increases. In doing so, this section also shows the evolution of another key element of technology use: strategies developed by older people to achieve their goals of being and feeling included, independent, social and competent when using technology. Section 6.1 is about interaction issues and strategies overcome with ICT experience. Section 6.2 deals with those that are persistent.

\subsection{Interaction issues overcome with ICT experience}

6.1.1. Older people use reading glasses. With experience, they make things on screen bigger occasionally and temporarily

Participants with no or little ICT experience firstly complained about the small size of text and icons and asked us about options to enlarge them. We showed them how to use on-screen accessibility features aimed at addressing mild-to-moderate visual impairments, such as screen magnifiers and changing the screen resolution, and enlarging pages font size in web browsers, which are all available in the Windows operating system. We observed that they tried these accessibility features, but returned to using their glasses, which were perceived as being more

\footnotetext{
${ }^{8}$ Quantitative testing involved standard asterisks, large ones, iconic labels and binary classification of fields. The latter had a significant effect on reducing the number of errors made by 88 older people who were novice users, while the former three did not show significant differences.

Please cite this version of the manuscript as: Sayago, S., Sloan, D., Blat, J. Everyday use of computer-mediated communication tools and its evolution over time: an ethnographical study with older people. Interacting with Computers, http://dx.doi.org/10.1016/j.intcom.2011.06.001
} 
NOTICE: this is the author's version of a work that has been accepted for publication in Interacting with Computers. Changes resulting from the publishing process, such as peer review, editing, corrections, structural formatting, and other quality control mechanisms may not be reflected in this document. Changes may have been made to this work since it was submitted for publication. A definitive version will be published in Interacting with Computers.

socially acceptable, or normalised - participants reported that some important members of their social circles, such as their children and grandchildren, also used reading glasses to use ICT, and that they felt more comfortable using the same technologies as them. Only those participants (around 20\%) for whom their glasses were not enough to effectively read from the computer screen used any of these accessibility options throughout the study.

With more ICT experience, all participants used these options at some point, especially when their reading glasses were not enough to conduct tasks that demanded high visual precision, such as clicking on the square dots to enlarge pictures while editing multimedia presentations.

[Researcher]: (notices that a participant is enlarging the page font size of her web-based e-mail). $H i$ (name of the participant), how are you doing? I thought that your reading glasses did you wonders

[Woman G, 80]: (sigh) They used to be very helpful, but now I've to admit that my eyes are getting older and I need the text a bit bigger. I'm using this option to make it slightly bigger...you see, that's much better now... but not too much bigger, my glasses are still of some use and I'm not blind, yet (smile)!

However, all the participants returned to their reading glasses when they completed these visually demanding tasks.

[Researcher]: (notices that a participant is altering the screen resolutions). Hi (name of the participant), I think you are about to change the resolution of the computer screen, where did you learn to do that?

[Man I, 68]: Yes, I want to make the screen a bit bigger because clicking on these little things to make the picture bigger is very difficult, even with my reading glasses. But don't worry, I'll change the screen again when I'm done. In one of the courses I took here some months ago I learned how to make such changes, and they come in handy when you're in trouble.

It is worth noting that our participants used other visually demanding technologies. For instance, around 200 of them owned mobile phones, which were not especially designed for older people 9 . Increasing font size in web browsers makes navigation much more difficult. However, when older people become confident with technology, they occasionally replace their reading glasses with on-screen accessibility options, and return to their glasses.

\subsubsection{They manage the mouse. The keyboard...is not for clicking}

Participants who had never used a mouse found it very difficult to use. $10 \%$ of them had previous ICT experience and used both hands or lifted the mouse to make the movements more precise. Around 10 of these participants also changed the behaviour of the mouse by changing the colour of the pointer and double-click speed. These participants with previous ICT experience reported having learned to use the mouse as a result of using it, i.e. they had not been instructed in its use. We observed that beginners developed very similar strategies over time. However, in their case, they learned to use the mouse by observing and talking with the more experienced participants.

Our participants considered using keyboard shortcuts (e.g. CTRL + C/V) and arrow keys to scroll down and up an accessibility aid. All of them pointed out that this use of the keyboard is not an alternative to the mouse for them, since they considered that others use the keyboard for typing and not for navigation. Thus, using the keyboard as a replacement for a mouse is considered abnormal behaviour by our participants, with resultant negative social inclusion connotations. We observed that, only with ICT experience, and when they were unable to use the mouse, did they rely on the keyboard. These results reinforce and extend those presented in

\footnotetext{
${ }^{9}$ The participants reported that mobile phones targeted at older people are very expensive and that they used the phones discarded by their children.

Please cite this version of the manuscript as: Sayago, S., Sloan, D., Blat, J. Everyday use of computer-mediated communication tools and its evolution over time: an ethnographical study with older people. Interacting with Computers, http://dx.doi.org/10.1016/j.intcom.2011.06.001
} 
NOTICE: this is the author's version of a work that has been accepted for publication in Interacting with Computers. Changes resulting from the publishing process, such as peer review, editing, corrections, structural formatting, and other quality control mechanisms may not be reflected in this document. Changes may have been made to this work since it was submitted for publication. A definitive version will be published in Interacting with Computers.

[33]: older people reject devices that hinder social inclusion. Instead, they develop, over time, their own strategies to use what the rest of the people use.

[Researcher]: Well, (name of the participant), I've noticed that you're an expert at computers.

[Man E, 70]: I wouldn't say so.

Researcher]: You thought you'd never be able to use them, right? But look at you now! The mouse was a nightmare... all the problems you had with this little beast, as you used to say, and now, you see...

[Man E, 70]: (big smile). This is very true, my friend. At the beginning, I was all thumbs and very negative, but with time, I've learned how to master the mouse, created my own way of playing this little beast... with two hands! I still have problems, you know, but I'm very happy to be able to use it... the same mouse you guy use!

6.1.3 Excessive functions make their learning hard, but when they feel confident, they use them

A common approach to designing better tools for older people is to provide them with very simple tools, which have reduced functionalities, as reviewed earlier. This is done to cope with their lack of ICT experience or compensate for cognitive difficulties. However, tools only for older people are at odds with their desire to feel and be socially included and competent ICT users.

[Researcher]: Did you know that you can make phone calls with the video chats and share documents with your grandchildren via the video chat as well?

[Man R, 75]: Oh, dear, I didn't know that. There are so many things you can do with this thing. I've got the phone to make phone calls... All I want to do is to see my grandchildren and listen to their voice.

[Researcher]: So, you would like to see a much simpler video chat?

[Man R, 75]: Ah...this sounds good. But I don't want to use a video chat for seniors, you know what I mean?

[Researcher]: Can you give me an example?

[Man R, 75]: Um...(think for a while) I want a motorbike that I can ride and make it my own, but I don't want a motorbike that can be ridden only by me! This would be useless, wouldn't it?

Over time, when they reported feeling in control of the technology, we observed that they used what they had regarded as excessive or inappropriate functions. This is aligned with the dynamic nature of experience discussed in [20, p. 19-27].

[Researcher]: Sorry to disturb you, but I haven't seen any participant using the BCC before. They even told me that this BCC was quite useless as they send e-mails only to people they know.

[Woman U, 67]: Oh, yes, I do agree with them. I'm probably the one odd out. I think that I know how to use e-mails now... I send, receive, send photos, so... I'm taking a step further!

[Researcher]: This sounds good. Would you have done the same a year ago?

[Woman U, 67]: No way. I didn't know how to do the basics, but once you learn and use the email, you know, you explore more things, use them to get an idea of what they are for...

Excessive or inappropriate functions mean different things depending on the experience of older people with ICT. Therefore, very simple technologies for them should be reviewed by considering the evolution of technology use.

\subsection{Time / Experience persistent issues}

Please cite this version of the manuscript as: Sayago, S., Sloan, D., Blat, J. Everyday use of computer-mediated communication tools and its evolution over time: an ethnographical study with older people. Interacting with Computers, http://dx.doi.org/10.1016/j.intcom.2011.06.001 
NOTICE: this is the author's version of a work that has been accepted for publication in Interacting with Computers. Changes resulting from the publishing process, such as peer review, editing, corrections, structural formatting, and other quality control mechanisms may not be reflected in this document. Changes may have been made to this work since it was submitted for publication. A definitive version will be published in Interacting with Computers.

6.2.1 Their memory is in their notes: they write down steps, words and areas

Independently of their ICT experience, all the participants took notes and relied on them to:

1) Learn to use a new tool: taking notes was their learning strategy

[Man A, 68]: I need to learn to send an e-mail to my son who is working in Madrid

[Researcher]: No problem. The first thing is to click on (A interrupts)

[Man A, 68]: Wait a second. I need to take notes, because if I don't write how to do things with the computer down, later on I won't remember how to do it. You'll never be here to help me/us, so I need to stick to things I can use on my own.

Reading books on how to use tools or computers, in general, was not their learning strategy. Only 50 participants showed us some books on tools (e.g. 'the bible of (name of the tool)') or on computing, all of which targeted at older people. The rest reported not reading books, user manuals or tutorials. We observed that no participant read them while using computers in Àgora. All of them relied on their notes, helpers and other participants. They also pointed out that the social atmosphere of Àgora contributed to a more effective learning to people of their age, as well as reducing isolation.

2) Help them remember how to carry out tasks, regardless of their frequency of tool use. One of these tasks is when to left or right click. The participants reported that their notes made them feel more confident in themselves.

[Researcher]: I can't believe you still read your notes to known when to click with the left or the right click of the mouse. You know more things than me about multimedia presentations and the mouse is still a problem? (smile)

[Woman F, 65]: I know, I know. But you know what? There might be some cable in my brain that is disconnected. I use computers everyday, but there are things that I don't get to have them 'in' or even worse, there are bad days where you simply can't use computers unless you've your notes with you. So, yes, I read my notes, any problem (smile)?

[Man T, 70]: I went on holidays for two weeks and I didn't use computers. Today, I think that I've lost all my "knowledge" because I don't quite remember how to make these pictures move in the presentation. Before going on holidays, I knew how to do it very well. But today...I must rely on my notes to make the pictures move on my own.

6.2.2 They do not hurry...ever!

Being afraid of breaking the computer by making mistakes wears off with experience. However, the consequences of making mistakes (e.g. losing important information, realisation that they are not truly independent ICT users and efforts to overcome the mistakes) do not.

Researcher]: We've been here together for 3 years. I've seen how you've progressed, from not knowing how to use the mouse to teaching other older people how to do video chats.

[Man T, 68]: I started to use computers with you. I've learned thousands of things, thank you very much. But, maybe, the most important one, is that you should never use them in a hurry

[Researcher]: You mean when you're learning?

[Man T, 68]: Always. If you do things quickly, you can lose an e-mail of your grandchildren or even a picture of your new grandson. Trying to find these things is very difficult: look at your notes, they aren't so accurate as they should be, scratching your head to remember something you should already know... uf! It's better to stay on the safe side.

[Researcher]: I see... (Interrupted by the participant)

Please cite this version of the manuscript as: Sayago, S., Sloan, D., Blat, J. Everyday use of computer-mediated communication tools and its evolution over time: an ethnographical study with older people. Interacting with Computers, http://dx.doi.org/10.1016/j.intcom.2011.06.001 
NOTICE: this is the author's version of a work that has been accepted for publication in Interacting with Computers. Changes resulting from the publishing process, such as peer review, editing, corrections, structural formatting, and other quality control mechanisms may not be reflected in this document. Changes may have been made to this work since it was submitted for publication. A definitive version will be published in Interacting with Computers.

[Man T, 68]: And, also, you believe you know how to and even show off a little, but then you realise you still need help; this is not bad, but you feel sad and disappointed, as you see that you'll always need help.

\section{Some implications for design}

We agree with the view of Dourish [15] that implications for design should not necessarily be the main criteria for judging the value of ethnographical studies in HCI. However, we consider that providing tentative examples of some of the implications which can be drawn from this ethnographical study for designing, understanding and evaluating older people's experiences with technology, can help designers and researchers identify relevant aspects to build better technologies.

\subsection{Tools only for older people?}

Designing special tools for older people might not be a good approach. First, the apparent advantages of tailoring technologies to their special needs (e.g. enlarging text size) observed in laboratory conditions are not so evident in prolonged use of tools out of them. For instance, we have revealed the negative reaction of our participants when they were asked about a special video chat. We have also showed their persistent use of the mouse and reading glasses, rather than alternative input devices and in-built accessibility options. Older people are old, but they do not want to be regarded as or feel different. Second, the longitudinal analysis has revealed that functions and options which might be regarded as excessive, or inappropriate, are or can be used over time. On-screen accessibility options are used occasionally, for instance. The use of these functions and options happens with ICT experience, so reducing complexity might deprive older people of possibilities to improve and extend what they do.

Layer-based interfaces [2], training wheels [7], and more recent and ongoing work on adaptive interfaces and user profiling in the SUS-IT project [36] can be more inclusive in their design approaches. For instance, rather than enlarging (and fixing) the size of system elements because an older person is using the technology, which leads to social exclusion, making in-built accessibility options more accessible and letting the (older) person be more aware of them and use them when needed can foster inclusion.

\subsection{Design opportunities for inclusion and richer communication with family and friends}

We have shown the pervasiveness and importance of note-taking. Enabling or supporting it in user interfaces can lead to more inclusive ones, since note-taking is unlikely to be an exclusive practice. Some aspects which have emerged from our study and we consider can be used to inspire the design such interfaces are: access to the notes whenever and wherever they use the technology; personalisation related to the tools (e.g. clicking areas, terminology, steps to conduct tasks); sharing notes among the social circles. The designs could be focused on one or more of these aspects. They could also be formulated as add-ons to existing tools or far-looking ones (e.g. electronic ink), for instance.

We have already reviewed examples of new tools to facilitate different forms of (extended) family communication $[6,25,28]$. Apart from the use of photos and calendars explored in these studies, the social, emotional and putting something of themselves into communication components of the everyday use discussed can open up more design opportunities to support and enrich communication with family and close friends.

\subsection{Beyond factors: positive and social actors, more research in out-of-laboratory conditions}

Factors such as age-related changes in functional abilities and overall lack of ICT experience have a clear impact on technology use by older people. However, a design approach that is limited to compensating for these factors is not enough to create a genuinely positive impact on user acceptance amongst older people. The prolonged use of tools in out-of-laboratory conditions provides a richer picture of interaction issues. For instance, this paper has shown

Please cite this version of the manuscript as: Sayago, S., Sloan, D., Blat, J. Everyday use of computer-mediated communication tools and its evolution over time: an ethnographical study with older people. Interacting with Computers, http://dx.doi.org/10.1016/j.intcom.2011.06.001 
NOTICE: this is the author's version of a work that has been accepted for publication in Interacting with Computers. Changes resulting from the publishing process, such as peer review, editing, corrections, structural formatting, and other quality control mechanisms may not be reflected in this document. Changes may have been made to this work since it was submitted for publication. A definitive version will be published in Interacting with Computers.

motivations, efforts, perceptions of being cared and important, social circles, inclusion, socialisation, independence and competence. Combining studies in laboratory conditions with those conducted out of them and during prolonged periods of time, which are scarce and there should be more of them, could provide a much richer understanding of older people as ICT users and design better technologies for all of us.

Considering interaction issues beyond factors means turning older people into social actors. Concurring with the claim made by Hanson in her laboratory-based study of older people looking for online information [19], we consider that research should focus more on their strengths than on their weaknesses, resulting in a more positive view of these social actors. Our results show that a large number of older people can use different tools and overcome numerous interaction issues. This reflects their motivation, intelligence and efforts, which should not be regarded as a lack of need for more research to make ICT much more usable and accessible.

\section{Discussion}

\subsection{On methods and results}

We considered that older people's technology use in out-of-laboratory conditions during an extended period of time should be much better understood, and traditional long-term ethnography could help us achieve this understanding. The results of this paper seem to confirm it.

The findings are based on our first-hand conversations with and in-situ observations of older people using CMC tools. We have carefully distinguished between participants reported and we observed throughout the paper, as rigorous ethnographical research requires confirming conversations with observations, and vice versa. Most of our observations are expressed through the voices of the participants, since they provide, in our opinion, better and deeper insights of the issues they experienced. We have also complemented the voices of the participants with a web page containing a set of photos of real technology use by them ${ }^{10}$.

Using the voice of older people to express categories resulting from qualitative analysis is borrowed from [39]. However, our results combine observations and conversations into categories emerging from the data, unlike in [39], wherein the conversations with older people are analysed by using learned helplessness as a theoretical lens. Our results are completely at odds with theirs. Our participants make a very rich use of CMC tools across different ones. They are motivated and want to be and feel included, social, independent and competent ICT users. We have also provided more details of this use which can help to create better tools, such as perceptions of usefulness and being cared and important; content and pattern of communication, social practices established around the use of tools, efforts and privacy issues.

We have been immersed in a community of older people who have taken the step to (learn to) use ICT. Thus, we do not claim that our results are valid for the less motivated or digitally disengaged (e.g. [39]). We expect to address this issue soon. However, our results might be relevant to HCI research on, for instance, engaging older people in ICT [9] or sustaining their use of ICT [36], and other areas, such as intergenerational relationships.

\subsection{On time in HCI}

Classical ethnography was crucial to show the evolution of use and interaction issues over time. We consider that some of the categories, which have emerged from the ethnographical study, such as independence, resonate with some of the top ten psychological needs in Hassenzahl [20, p. 46], suggesting a framework to understand user experiences. Other categories, such as timepersistent interaction issues and strategies of use, appear to be new with respect to previous frameworks for user experience [22, 20], and useful to understand tools use and design better technologies.

\footnotetext{
${ }^{10} \mathrm{http}: / /$ www.dtic.upf.edu/ ssayag/ToolsUseEvolution/

Please cite this version of the manuscript as: Sayago, S., Sloan, D., Blat, J. Everyday use of computer-mediated communication tools and its evolution over time: an ethnographical study with older people. Interacting with Computers, http://dx.doi.org/10.1016/j.intcom.2011.06.001
} 
NOTICE: this is the author's version of a work that has been accepted for publication in Interacting with Computers. Changes resulting from the publishing process, such as peer review, editing, corrections, structural formatting, and other quality control mechanisms may not be reflected in this document. Changes may have been made to this work since it was submitted for publication. A definitive version will be published in Interacting with Computers.

Our results stress the importance of fine details and their evolution in technology use. Older people decide when and how they use excessive and inappropriate functions. Feeling confident in their abilities to use ICT modifies their use of them. We have revealed that a large number of today's older people, with time and experience, develop strategies to effectively overcome difficulties perceiving visual information and using the mouse, unlike issues related to cognitive decline, which are more time-persistent, independent of skills and practice, and require other strategies, such as note taking and further tools use.

The results allow us to start to a discussion on ICT use when most of today's young adults grow older. They will likely develop strategies to manage and overcome difficulties reading from the (computer) screen or using input devices, as they will build upon their experiences of using contemporary ICT. However, when they are exposed to unfamiliar ICT, issues due to declines in fluid intelligence [10] will become important. Efficiency ('work' mode) will probably be changed for pleasure ('retirement' mode). The next generation will also face excessive or inappropriate functions, as a result of technology evolution. They will probably overcome them by note-taking and developing other strategies as a result of their use of new ICT. Inclusive strategies (e.g. putting reading glasses on or taking notes) are likely to remain valid. Today's young adults might feel 'extraordinary' with unfamiliar ICT - or the way they are designed to them.

\subsection{Some other limitations}

We have not explored the participants' lack of interest in, or awareness of, emerging web-based social networking technologies because we decided to concentrate on those tools that they did use or wanted to use to communicate with their social circles. We have not addressed age or gender differences either in the use of or evolution of interaction issues because we did not find any.

\section{Conclusions and future work}

Socialisation, independence and inclusion are relevant elements of e-mail [33] and other CMC tools use. Being old and a competent ICT user is a new and related aspect discussed in this paper. Contrary to, perhaps, common and current stereotypes of older people as ICT users, we have revealed and explained the inclusive, competent, social and active use a large number of them make of a wide array of CMC tools. The importance of getting in touch with their loved ones does not wear off over time. Keeping in touch with them is so important that it encourages them to make the effort to learn and use ICT.

Interaction issues due to cognition limit more severely the use of tools than those due to difficulties using the mouse or perceiving visual information. The evolution of interaction issues and strategies older people adopt to overcome them with increasing ICT experience have been unveiled. Difficulties using ICT due to or related to cognition are the most severe, timepersistent, and independent of experience and practice with technology. Taking notes is the strategy adopted by older people for learning new technology and coping with difficulties remembering steps, terms and important interactive areas. Problems due to perceiving visual input or using the mouse are overcome with experience. Their persistent goal of being included and competent users encourages older people to put their reading glasses on to read from the computer screen and to use both hands to control the mouse. With experience, in-built accessibility options at operating systems, web browsers, and excessive or inappropriate functions are also used when older people feel they need to use them or want to extend what they do and know about technology.

The longitudinal aspect of the data gathered and analysed has provided us with an opportunity to discuss a number of interaction issues that the next generation of older people will probably encounter. Cognitive-related interaction issues are bound to hinder their use most severely.

Please cite this version of the manuscript as: Sayago, S., Sloan, D., Blat, J. Everyday use of computer-mediated communication tools and its evolution over time: an ethnographical study with older people. Interacting with Computers, http://dx.doi.org/10.1016/j.intcom.2011.06.001 
NOTICE: this is the author's version of a work that has been accepted for publication in Interacting with Computers. Changes resulting from the publishing process, such as peer review, editing, corrections, structural formatting, and other quality control mechanisms may not be reflected in this document. Changes may have been made to this work since it was submitted for publication. A definitive version will be published in Interacting with Computers.

Difficulties due to age-related sensory impairments are more likely to be managed as a result of their ICT experience and their desire to remain ordinary users with tomorrow's ICT.

These results show the potential of ethnography to improve considerably current knowledge in HCI research with older people.

We are conducting a long-term ethnographical study of ICT use with a different cohort of older people in Dundee (Scotland). This study should allow us to understand how different or similar the results of use, individual and social interaction issues, and evolution of both aspects are in two a priori different cohorts of older people.

We are conducting rapid ethnography [27] to understand the potential of geo-positioning ICT to foster independent living and socialisation amongst the older population, and the interaction issues faced when using technologies such as Google Maps ${ }^{11}$. This research should allow us to understand better different forms of ethnography and their relationship, and the use and interaction issues of location technologies and social networking tools.

In a pilot study, a professional designer used the results of the study of e-mail use [33] to design a prototype of a more inclusive e-mail tool [26]. We are planning to conduct a more significant experiment, which will involve design students and address the important question of how ethnographical results are and can be more effectively translated (i.e. both communicated and used) into design/s.

We also intend to design prototypes of CMC tools that allow both older people and adults near retirement to take and share notes. We aim to evaluate the extent to which these interfaces increase inclusion and accommodate to their dynamic interaction issues. We plan to combine classical ethnography with quantitative studies in this work.

\section{Acknowledgements}

We are indebted to Àgora and all our participants for allowing us to be part of their lives and share their experiences of using ICT with the rest of the world. We are also very grateful to Paula Forbes for improving our English and ideas, and the reviewers and editor of this journal for their careful, detailed and stimulating reviews. We also acknowledge the support from the Commission for Universities and Research of the Ministry of Innovation, Universities and Enterprise of the Autonomous Government of Catalonia.

\section{References}

[1] Ames, M. G., Go, J., Kaye, J., Spasojevic, M., 2010. Making love in the network closet: the benefits and work of family videochat. In: Proceedings of the 2010 ACM Conference on Computer Supported Cooperative Work (Savannah, Georgia, USA, February 06 - 10, 2010), 145-154.

[2] Baecker, Booth, S., Jovicic, J., Moore, G. 2000. Reducing the gap between what users know and what they need to know. In: Proceedings of the ACM Conference on Universal Usability, New York, $17-23$.

[3] Beyer, H., Holtzblatt, K., 1998. Contextual Design: Defining Customer-Centered Systems. Morgan Kauffmann Publishers, USA.

[4] Blomberg, J., Burrell, M., Guest, G., 2003. An ethnographic approach to design. In: Jacko, J.A., Sears,A. (Eds.), The Human-Computer Interaction Handbook: Fundamentals, Evolving Technologies and Emerging Applications. Lawrence Erlbaum Associates, London, 964-987.

[5] Boyd, D. 2008. Taken Out of Context. American Teen Sociality in Networked Publics. PhD dissertation. University of California-Berkeley, School of Information. http://www.danah.org/papers/

\footnotetext{
${ }^{11}$ We are conducting this research within the framework of the Life2.0 project [24], wherein ethnographical research is being conducted in four EU countries and industrial partners are involved to develop an online platform with accessible and useful geo-positioning ICT for older people and their social circles, including helpers.

Please cite this version of the manuscript as: Sayago, S., Sloan, D., Blat, J. Everyday use of computer-mediated communication tools and its evolution over time: an ethnographical study with older people. Interacting with Computers, http://dx.doi.org/10.1016/j.intcom.2011.06.001
} 
NOTICE: this is the author's version of a work that has been accepted for publication in Interacting with Computers. Changes resulting from the publishing process, such as peer review, editing, corrections, structural formatting, and other quality control mechanisms may not be reflected in this document. Changes may have been made to this work since it was submitted for publication. A definitive version will be published in Interacting with Computers.

[6] Brush, A. B., Inkpen, K. M., and Tee, K., 2008. SPARCS: exploring sharing suggestions to enhance family connectedness. In: Proceedings of the 2008 ACM Conference on Computer Supported Cooperative Work (San Diego, CA, USA, November 08 - 12, 2008), 629-638.

[7] Carroll, J.M., Carrithers, C. 1984. Training wheels in a user interface. Communications of the ACM, 27(8)

[8] Charmaz, K., Mitchell, R.G., 2007. Grounded theory in ethnography. In: Atkinson, P., Coffey, A., Delamont, S., Lofland, J., Lofland, L.(Eds.), Handbook of Ethnography. SAGE Publications, London, 160-175.

[9] Coleman, G., Gibson, L., Hanson, V., Bobrowicz, A., McKay, A. 2010. Engaging the disengaged: How do we design technology for digitally excluded older adults? In: Proceedings of the 8th ACM Conference on Designing Interactive Systems (Eds. K. Halskov and M.G. Petersen), Aarhus, Denmark, 175-178

[10] Craik, F. I. M., and Salthouse, T. A., 2000. The handbook of aging and cognition (Revised Edition). Lawrence Erlbaum Associates, Mahwah, NJ.

[11]Czaja, S.J., and Lee, C.C. Designing Computer Systems for Older Adults, in Jacko, J.A. and Sears, A. eds. The Human-Computer Interaction Handbook: Fundamentals, Evolving Technologies and Emerging Applications, Lawrence Erlbaum Associates, Mahwah, NJ 2003, 413-428

[12] Damodaran, L., and Olphert, W., 2010. Sustaining Digital Engagement: Some Emerging Issues. Digital Futures, October 11 - 12, 2010, Nottingham, UK

[13] Dickinson, A., and R. L. Hill., 2007. Keeping In Touch: Talking to Older People about Computers and Communication. Educational Gerontology, 33(8), 613-630.

[14]Dickinson, A., Arnott, J.L., Prior, S., 2007. Methods for human-computer interaction research with older people. Behaviour \& Information Technology, 26(4), 343-352

[15] Dourish, P., 2006. Implications for design. In: Proceedings of the SIGCHI Conference on Human Factors in Computing Systems (Montréal, Québec, Canada, April 22 - 27, 2006), 541-550

[16]Fetterman, D. 2010. Ethnography. Step-by-Step. SAGE Publications. Applied social research methods series, London (UK).

[17] Gibson, L., Moncur, W., Forbes, P., Arnott, J., and Martin, C., 2010. Designing Social Networking Sites for Older Adults. In: BSC HCI 2010, Dundee (Scotland).

[18]Hanson, V. L., 2009. Age and Web Access: The Next Generation. In: Proceedings of the 2010 W4A Technical, Madrid (Spain), 7-15

[19] Hanson, V. L. 2010. Influencing technology adoption of older adults. Interacting with Computers, 502-509.

[20] Hassenzahl, M. 2010. Experience Design: Technology for All the Right Reasons. Synthesis Lectures on Human-Centered Informatics, John M. Carroll (Editor), Morgan \& Claypool, San Rafael, California, USA.

[21] Hawthorn, D.,2000. Possible implications of aging for interface designers. Interacting with Computers, 12, 507-528.

[22] Karapanos, E., Zimmerman, J., Forlizzi, J., and Martens, J., 2009. User Experience Over Time: An Initial Framework. In: Proceedings of CHI 2009 - User Experience, Boston (USA), 729-738.

[23] Khoo, Eng Tat, Merritt, T., and Cheok, A. D., 2009. Designing physical and social intergenerational family entertainment. Interacting with Computers, 21(1-2), 76-87

[24]Life 2.0, 2011: Geographical positioning services to support independent living and social interaction of elderly people (CIP ICT PSP - 2009 - 4 - 270965). http://www.life2project.eu/.

[25]Lindley, S. E., Harper, R., and Sellen, A., 2009. Desiring to be in touch in a changing communications landscape: attitudes of older adults. In: Proceedings of the $27^{\text {th }}$ international Conference on Human Factors in Computing Systems (Boston, MA, USA, April 04 - 09, 2009), 1693-1702

Please cite this version of the manuscript as: Sayago, S., Sloan, D., Blat, J. Everyday use of computer-mediated communication tools and its evolution over time: an ethnographical study with older people. Interacting with Computers, http://dx.doi.org/10.1016/j.intcom.2011.06.001 
NOTICE: this is the author's version of a work that has been accepted for publication in Interacting with Computers. Changes resulting from the publishing process, such as peer review, editing, corrections, structural formatting, and other quality control mechanisms may not be reflected in this document. Changes may have been made to this work since it was submitted for publication. A definitive version will be published in Interacting with Computers.

[26] Malón, Guillermo, 2010. Designing the user interface of a webmail for older people: translating ethnographical data into design solutions. CSIM (Interdisciplinary Master in Cognitive Systems and Interactive Media) Master Thesis. Universitat Pompeu Fabra (Barcelona, Spain).

[27] Millen, D. 2000. Rapid Ethnography: Time Deepening Strategies for HCI Field Research. In: Proceedings of DIS 2000, 280-286. New York, USA

[28] Mynatt, E. D., Rowan, J., Craighill, S., and Jacobs, A., 2001. Digital family portraits: supporting peace of mind for extended family members. In: Proceedings of the SIGCHI Conference on Human Factors in Computing Systems (Seattle, Washington, United States), 333-340.

[29]Pfeil, U., Panayiotis, Z., and Stephanie, W., 2009. Older adults' perceptions and experiences of online social support. Interacting with Computers, 21(3), 159-172.

[30] Prior, S., Arnott, J., and Dickinson, A., 2008. Interface metaphor design and instant messaging for older adults. In: Proceedings of CHI '08 Extended Abstracts on Human Factors in Computing Systems (Florence, Italy, April 05 - 10, 2008), 3747-3752.

[31] Quadrello, T., Hurme, H., Menzinger, J., Smith, P.K., Veisson, M., Vidal, S., Westerback, S., 2005. Grandparents use of new communication technologies in a European perspective. European Journal of Ageing, 2, 200-207

[32] Randall, D., Harper, R., Rouncefield, M., 2007. Fieldwork for Design. Theory and Practice. Springer, London.

[33] Sayago, S., and Blat, J., 2010. Telling the story of older people e-mailing: an ethnographical study, International Journal of Human-Computer Studies, 68, 105-120

[34] Sayago, S., Guijarro, J., Blat, J. 2010. Selective attention in web forms: an exploratory case study with older people, Behaviour and Information Technology, 17 May 2010 (iFirst)

[35] Selwyn, N., Gorard, S., Furlong, J., Madden, L., 2003. Older adults' use of information and communication technology in everyday life. Ageing \& Society, 23, 561-582.

[36] Sloan D., Atkinson, M. T., Machin, C. H. C., Li, K., 2010. The Potential of Adaptive Interfaces as an Accessibility Aid for Older Web Users. In: Proceedings of 2010 International Cross-Disciplinary Conference on Web Accessibility (W4A) (Raleigh, USA, 26-27 April), 1-10

[37] Tee, K, A J B Brush, and K M Inkpen, 2009. Exploring communication and sharing between extended families. International Journal of Human-Computer Studies, 67(2), 128-138.

[38] Thurlow, C., Lengel, L., Tomic, A. 2009. Computer-Mediated Communication. Social interaction and the Internet. SAGE, London

[39] Turner, P., Turner, S., Walle, V. 2007. How older people account for their experiences with interactive technology. Behaviour \& Information Technology, 26(4), 287-296

[40] Vanden Abeele, V. A. and Van Rompaey, V., 2006. Introducing human-centered research to game design: designing game concepts for and with senior citizens. In: Proceedings of CHI '06 Extended Abstracts on Human Factors in Computing Systems (Montréal, Québec, Canada, April 22 - 27, 2006). CHI '06, 1469-1474.

[41]Voida, A., and Greenberg, S. 2011. Console Gaming Across Generations: Exploring Intergenerational Interactions in Collocated Console Gaming. Universal Access in the Information Society (in press)

[42]Xie, B., 2008. Multimodal Computer-Mediated Communication and Social Support among Older Chinese Internet Users, Journal of Computer-Mediated Communication, 13(3), 728-750.

Please cite this version of the manuscript as: Sayago, S., Sloan, D., Blat, J. Everyday use of computer-mediated communication tools and its evolution over time: an ethnographical study with older people. Interacting with Computers, http://dx.doi.org/10.1016/j.intcom.2011.06.001 